\title{
Itinerários da Educação Física na Escola: O caso do Colégio Estadual do Espírito Santo
}

\author{
Valter Bracht* \\ Rosely Maria da Silva Pires ** \\ Ana Flávia Sofiste ${ }^{* * *}$ \\ Sabrina Poloni Garcia**** \\ Felipe Quintão de Almeida**** \\ Elisa Barcellos da Cunha e Silva*** \\ Evânia Nunes de Angeli*** \\ Mauro Sérgio da Silva****
}

Resumo: Esse estudo analisa o itinerário da disciplina Educação Física no Colégio Estadual do Espírito Santo, no período de 1970 a 2000, procurando: identificar o discurso construído por ela para legitimar-se no currículo daquela escola; examinar as possíveis mudanças de sentido da sua presença no currículo; identificar os principais fatores internos e externos que influenciaram as características assumidas pela disciplina; analisar as soluções pensadas para superar a atual crise da disciplina no colégio. $O$ estudo de caso realizado indica uma forte dependência da legitimidade e do status da disciplina Educação Física, dos desdobramentos da prática esportiva e das políticas públicas voltadas ao esporte competitivo.

Palavras-chave: escola, disciplinas escolares, educação física.

O entendimento da função ou das funções que a disciplina Educação Física vem cumprindo, no âmbito da instituição escolar no Brasil, concentra boa parte dos esforços teóricos recentes da área. No campo dessa produção, a década de 80 do século passado é vista como o momento em que a leitura dessa função é feita de forma mais sistemática, a partir de um viés sociológico de cariz

\footnotetext{
* Doutor em Ciências do Ciência do Esporte, com concentração em Sociologia do Esporte e Professor da Universidade Federal do Espírito Santo Coordenador do LESEF. Pesquisa apoiada pelo CNPq.

** Mestranda em Educação na UFF e professora do Curso de Educação Física da ESFA.

*** Licenciados em Educação Física - UFES

**** Licenciado em Educação Física - UFES e professor da Rede Municipal de Cariacica-ES.
}

Movimento, Porto Alegre, v. 11, n. 4, p.9-21, janeiro/abril de 2005 
marxista ou, mais genericamente, de uma teoria crítica da sociedade. Assim como na Pedagogia, também na Educação Física, ${ }^{1}$ a teoria marxista torna-se hegemônica como instrumental de análise, ao menos entre aqueles que se auto-intitulavam "críticos".

Mais recentemente, estudos têm procurado rever criticamente aquelas análises (CAPARROZ, 1997; OLIVEIRA, 2001; GARIGLIO, 2002), movimento esse que, mais uma vez, apresenta-se também no campo mais amplo da Pedagogia. Essas análises, em termos gerais, criticam o caráter fortemente esquemático das análises marxistas da década de 80, que teriam feito com que a Educação Física parecesse um objeto totalmente determinado pelas macroestruturas (econômicas e políticas), nas quais os sujeitos não teriam a possibilidade de resistir a essas determinações macroestruturais, em que o cotidiano escolar, com suas fissuras, contradições, idiossincrasias, focos de resistência, teria sido amplamente ignorado. Tais críticas estão ancoradas em estudos que circulam fortemente nos programas de pós-graduação em Educação no Brasil nos últimos anos, e que se vinculam, entre outras, às perspectivas da nova Sociologia Crítica do Currículo e, principalmente, à da História das Disciplinas Escolares.

Por influência de mudanças metateóricas, que não nos é possível discutir aqui, passamos a dar destaque na compreensão da escola, aos aspectos "internos" da sua dinâmica, como reivindicado, por exemplo, por Juliá (2002), para quem a Histórica das Disciplinas Escolares, para ser realmente operatória, deve partir mais dos fenômenos e mecanismos "internos" à escola do que da aplicação de explicações "externas" e pouco convincentes, sobre essas mesmas escolas. Gariglio (2002, p. 85) entende que “[...] é necessário que se chame a atenção para a necessidade de se situarem as relações de mudança no interior da comunidade educacional em oposição às condições de mudanças, especificamente provenientes do contexto econômico existente e, geralmente, do concomitantemente fluxo e refluxo do clima de opinião pública". Já Oliveira (2001) reivindica a consideração dos professores de Educação Física como sujeitos capazes de divergir, resistir, burlar e (re)significar as políticas educacionais oficiais e mais gerais no âmbito do cotidiano escolar.

Atentos a essas críticas e mesmo para avaliar o seu alcance, entendemos que é importante desenvolver estudos empíricos nessa direção. Assim sendo, realizamos pesquisa sobre o itinerário da

1 Basicamente como reflexo das discussões no âmbito mais geral da Pedagogia.

Movimento, Porto Alegre, v. 11, n. 4, p.9-21, janeiro/abril de 2005 
disciplina Educação Física nas últimas três décadas do século passado, no Colégio Estadual do Espírito Santo, que é a mais importante escola pública estadual de segundo grau do Estado, procurando identificar, especialmente, como a Educação Física constrói seu discurso e prática na sua relação com as influências macroestruturais e com a sua comunidade interna. O estudo visa colaborar, num sentido mais amplo, com um melhor entendimento do processo de escolarização de saberes e práticas, no que diz respeito à dinâmica influenciadora de fatores externos e internos à instituição escolar. Em termos específicos, pretende auxiliar no entendimento do processo de legitimação da Educação Física como disciplina escolar, bem como dos mecanismos acionados para superar ou não a sua propalada crise.

\section{Aporte teórico-metodológico}

As discussões realizadas neste texto tomam como base empírica dados obtidos num estudo de caso, qual seja, o Colégio Estadual do Espírito Santo, instituição de ensino de segundo grau, com mais de 95 anos de existência. Nossa atenção recaiu sobre o itinerário da Educação Física nos últimos trinta anos (décadas de 70, 80 e 90 do século XX).

Para a obtenção dos dados, utilizamos como técnicas de coleta a entrevista e a análise documental. Esta última envolveu basicamente os registros das pautas ou cadernos de chamada de alunos da disciplina de Educação Física, no período compreendido entre os anos de 1970 e 2000, e os planos de trabalho pedagógico dos anos de 1999 e 2000. As pautas foram localizadas no arquivo do colégio e os planos de trabalho foram obtidos com os próprios professores. Foram entrevistadas onze pessoas: dois professores, três ex-professores de Educação Física, dois ex-alunos, um ex-diretor, a diretora atual, uma ex-supervisora e uma coordenadora pedagógica.

As questões levantadas e eleitas para serem discutidas, a partir do material empírico, foram suscitadas basicamente pelos estudos situados no âmbito da história das disciplinas escolares, mormente os estudos de Chervel (1990), Goodson (1990), Santos (1990, 1994) e Juliá (2002). Neste texto, a discussão terá como pano de fundo a questão da legitimação da Educação Física como componente curricular. Num plano mais específico, discutiremos: as características da Educação Física, sua aproximação e/ou distanciamento de uma disciplina escolar típica (saberes, instrumentos técnicos, etc.);

Movimento, Porto Alegre, v. 11, n. 4, p.9-21, janeiro/abril de 2005 
as possíveis alterações no status da disciplina no período estudado (possíveis crises), sua dependência de aspectos de política esportiva e educacional; a possível influência da Pedagogia Crítica na Educação Física na reformulação da disci-plina no colégio.

\section{O itinerário da Educação Física no Colégio Esta- dual do Espírito Santo}

Não cabe aqui discutir o processo de escolarização da Educação Física. ${ }^{2}$ Basta lembrar que o pensamento médico foi fundamental para que a instituição escolar acolhesse a idéia de que um espaço pedagógico específico deveria ser destinado à Educação Física e que, malgrado as redefinições e (re)significações pelas quais passou, sua legitimação se alicerçou na presumível contribuição para a manutenção e melhoria da integridade biológica do ser humano por meio da exercitação física, propiciando efeitos positivos sobre a saúde dos educandos, contribuindo, assim, para o seu desenvolvimento integral. Com esse intuito, foram construídos métodos (ginásticos) que, além da ginástica e outras exercitações metódicas, incorporam rapidamente outras manifestações da cultura corporal de movimento, como os jogos, a dança e, principalmente, o esporte.

No caso do Colégio Estadual do Espírito Santo, as pautas da década de 70 (mais precisamente até 1977/78) indicam que o"conteúdo" das aulas de Educação Física se constituía basicamente dos métodos ginásticos, por exemplo, o método sueco, a calistenia, o método natural austríaco, o método francês. A partir de 1979 até o ano 2000, o conteúdo registrado nas pautas (presumivelmente desenvolvido nas aulas) passa a ser, quase na sua totalidade, o esporte, mais especificamente as modalidades esportivas. Os registros indicam que as modalidades esportivas eram ensinadas a partir dos chamados "fundamentos", sendo prevista uma preparação ginástica anterior (aquecimento) e uma atividade de jogo ao final de cada aula.

Aparentemente, a Educação Física no Colégio Estadual do Espírito Santo assumia as características gerais de uma disciplina, ou seja, apresentava, em proporções variáveis, os diferentes elementos constitutivos de uma disciplina, como propõe Chervel (1990). As entrevistas, no entanto, forneceram-nos indícios de que, na década

2 Para tanto, remetemos o leitor a duas teses de doutorado: Vago (1999) e Paiva (2003).

Movimento, Porto Alegre, v. 11, n. 4, p.9-21, janeiro/abril de 2005 
de 70, as atividades de aula, ou seja, aquelas atividades didáticas previstas para a disciplina Educação Física eram extremamente desprestigiadas na escola. Já nas décadas anteriores a de 70, mas principalmente nessa e início da década de 80, constrói-se no Colégio Estadual do Espírito Santo um universo esportivo paralelo à disciplina Educação Física, ou seja, cai paulatinamente o prestígio da atividade que se caracteriza como uma atividade didática típica de uma disciplina escolar (apresentação sistemática de conteúdo, exercícios e avaliação) e sobe o prestígio de uma atividade organizada menos a partir dos códigos escolares e mais com base em códigos esportivos.

Juliá (2002, p. 51) lembra que “[...] as finalidades das disciplinas nunca são unívocas. Procedem, normalmente, de arquiteturas complexas, nas quais estratos sucessivos, que se sobrepuseram a partir de elementos contraditórios, se mesclam". Esse parece ter sido o caso da disciplina Educação Física no Colégio Estadual do Espírito Santo. Os registros nas pautas na década de 70 e mesmo o discurso de professores de Educação Física da época indicam que a finalidade das aulas de Educação Física era entendida na perspectiva da aptidão física, conforme se manifestou o Professor G (2002).

O que acontecia na época [década de 70], a gente trabalhava muito especificamente com a parte de ginástica formativa mesmo porque, o conceito dessa parte ele estava distribuído em vários sistemas que era a ginástica calistênica, a ginástica austríaca e o método francês, e daí a gente trabalhava de uma forma bem padronizada sistemática que era [...] cada método tem uma diferenciação [...]. O que era importante para nós, naquela época é que antigamente a gente não dissociava a parte de formação corporal e fisiológica da parte de iniciação desportiva ou da prática esportiva formalmente.

Os planos de Desenvolvimento da Educação Física e do Desporto dos Governos Militares da década de 70 continham, em relação às finalidades da disciplina Educação Física, uma dubiedade: ela deveria continuar com seu objetivo de melhorar a aptidão física da população, mas também seria a base da pirâmide esportiva, portanto, competia-lhe, também, a iniciação esportiva visando a preparar futuros atletas para as representações nacionais de elite (OLIVEIRA, 2001). Essa dubiedade parece explicar o paradoxo entre o tipo de conteúdo registrado nas pautas e o fato de que, já na década de 70, o Colégio Estadual se notabilizava pelo seu desenvolvimento esportivo. Esse momento de transição dos métodos ginásticos para o esporte pode ser compreendido como a instalação de uma nova "vulgata", na expressão de Chervel (1990, p. 204):

Movimento, Porto Alegre, v. 11, n. 4, p.9-21, janeiro/abril de 2005 
Quando uma nova vulgata toma o lugar da precedente, um período de instabilidade se instala [...]. Os períodos de instabilidade são separados pelos períodos "transitórios", ou de "crise", em que a doutrina ensinada é submetida a turbulências. O antigo sistema ainda continua lá, ao mesmo tempo em que o novo se instaura: períodos de maior diversidade, onde o antigo e o novo coabitam, em proporçôes variáveis.

A ênfase na prática esportiva, com a criação dos Jogos Escolares Brasileiros (JEBs), com suas respectivas edições municipais e estaduais, vai reforçar a tendência de o esporte tornar-se o conteúdo hegemônico, quando não único, das aulas de Educação Física. A dimensão e visibilidade social que o esporte escolar alcançou em muitas cidades e estados de nosso país ${ }^{3}$ contribuiu para que a legitimação da Educação Física se deslocasse da aptidão física para a iniciação e prática esportiva.

Nas décadas de 70 e 80, o Colégio Estadual do Espírito Santo notabilizou-se por suas conquistas nos jogos escolares do Espírito Santo. Concomitantemente ao seu sucesso esportivo, uma outra atividade do Colégio ganhava reconhecimento social: a banda marcial, dirigida por um professor de Educação Física. O paralelo é pertinente, na medida em que ambos, apresentações da banda e conquistas esportivas, pelo reconhecimento social que desfrutavam, tinham um efeito interno de consolidação de um "nós", identidade coletiva, permitindo o sentimento de orgulho de pertencer a um Colégio capaz de grandes performances. Os depoimentos indicam que treinadores (nem sempre professores de Educação Física) e atletas eram considerados ídolos e heróis pela comunidade escolar. A participação nos jogos escolares mobilizava a escola como um todo: aulas eram canceladas, torcidas eram organizadas para acompanhar os jogos das equipes da escola, como se pode perceber nos depoimentos que seguem:

Antigamente a Educação Física era colocada num patamar de respeito, exatamente pela evidência esportiva que tinha a escola e também porque a escola integra a sua comunidade aos jogos, então você, apesar de ficar numa prática de quadra, quando olhasse, ia para alguma participação esportiva e muitos professores também estavam no ginásio, eles percebiam o fruto do seu trabalho, a forma como você se empenhava, a questão ética. (PROFESSOR G.)

[...] podia-se apreciar de seus corredores omovimentona piscina eouviro rataplan, plan, plan dos suados ensaios da banda do colégio. O entusiasmo do professor $V$.

3 Em muitos Estados, os jogos escolares estaduais são, ainda hoje, uma das mais importantes competicões esportivas - como é o caso do Rio Grande do Norte e do importantes competiço in esportivas - como e o caso do Rio Grande do Norte e do Sergipe -, mobilizando intensamente a comunidade escolar e esportiva do Estado. Conquistas esportivas nesse âmbito significam aquisição de importante capi-
tal simbólico para as escolas.

Movimento, Porto Alegre, v. 11, n. 4, p.9-21, janeiro/abril de 2005 
G. e sua persistência contagiavam os jovens que brilhavam nas passeatas da cidade. A banda era cartão de visita do colégio. Ganhou prêmios, viagens, representando o Espírito Santo em outros estados (EX-SUPERVISORA H.).

Mas as equipes não eram formadas e treinadas nas próprias aulas de Educação Física, naquelas atividades didáticas que configuram as aulas dessa disciplina. Construiu-se uma estrutura para além daquela convencional de uma disciplina escolar. Treinadores eram contratados, inclusive pelo Grêmio Estudantil, para treinar as equipes do Colégio. Os alunos que participavam dos treinamentos eram dispensados das aulas de Educação Física e espaços e horários específicos eram destinados aos treinamentos, conforme exemplifica o depoimento a seguir:

Bom, trabalhávamos com uma metodologia de treinamento, treinamento para a prática desportiva, que a gente colocava um professor especializado só para treinamento, para a prática esportiva. Antigamente, no Estado, pelo menos no Colégio Estadual, a gente tinha um professor específico só para treinamento, ou seja, você trabalhava com os alunos eos alunos que se destacavam como atleta, os que tinham uma performance já destacada, eles ficavam exclusivamente com um professor que trabalhava só com a parte de treinamento [...] ele ficava inteiramente à disposição só para fazer treinamento visando à competição esportiva fazia o horário específico dele, o seu planejamento e recebia sua remuneração mensal só para dar treinamento (PROFESSOR G.).

Se não cairmos na tentação, conforme alerta Juliá (2002), de entendermos que o que não está formalizado como disciplina não está presente no currículo escolar, podemos dizer que o esporte, para além e concomitantemente com a disciplina Educação Física, fazia parte integrante do currículo (no sentido ampliado) do Colégio Estadual do Espírito Santo. Podemos perguntar, então: de que forma a prática esportiva, vinculada às competições esportivas, estava integrada ao projeto pedagógico do Colégio Estadual? Que tipo de relação existia entre essa prática e a prática pedagógica ligada à disciplina de Educação Física? Em que medida a prática esportiva voltada às competições não poderia ser considerada parte integrante da disciplina Educação Física? O que legitimava uma e outra? Em que medida a legitimidade da prática esportiva se transferia também para a Educação Física?

Tudo leva a crer que a prática esportiva vinculada às competições se legitimava a partir dos códigos propriamente esportivos e não educacionais. ${ }^{4} \mathrm{O}$ sucesso do esporte do Colégio

4 Aqui estamos trabalhando com a perspectiva sociológica da autonomia dos campos ou sistemas sociais. Os diferentes sistemas sociais autônomos constroem

Morimento, Porto Alegre, v. 11, n. 4, p.9-21, janeiro/abril de 2005 
Estadual era medido pelo sucesso esportivo, ou seja, pelo número de medalhas e troféus. A legitimação dessa prática no colégio vinculava-se, então: à mobilização dos alunos; ao clima de festa que colaborava para construir na escola; ao sentimento de sucesso que despertava na sua comunidade e ao sentimento de admiração que suscitava na comunidade extra-escolar; e ao correspondente prestígio social que angariava para o colégio. Enquanto isso, a legitimidade da disciplina Educação Física ficava ligada à idéia do desenvolvimento da aptidão física, da sua contribuição para a sociabilização dos alunos e à identificação de possíveis talentos esportivos. A relação entre as aulas de Educação Física e a prática esportiva ligada às competições era bastante tênue e, em pelos menos um aspecto, de subordinação daquela a esta: identificar os alunos com potencial esportivo. Aulas e treinamentos eram separados, atletas não eram alunos nas aulas de Educação Física. ${ }^{5}$ Em muitos casos, os próprios professores não eram os treinadores. De qualquer forma, o status dos professores ligados à Educação Física e ao esporte da escola foi bastante alto durante o período em que o engajamento (com sucesso) do Colégio Estadual nas competições esportivas foi intenso. Mais complexa é a questão da transferência da legitimidade auferida pelo esporte para a disciplina Educação Física, o que discutiremos à frente.

Podemos observar aqui como uma diretriz de política pública, no caso federal, com seu incentivo aos jogos escolares, influenciou decisivamente a configuração do cotidiano escolar. Essa influência e outras ligadas à política educacional mais ampla puderam ser percebidas a partir de outros desdobramentos.

O prestígio social e educacional desfrutado pelo Colégio Estadual do Espírito Santo até a década de 70 deteriora-se rapidamente a partir de então, principalmente na década 80. Essa deterioração está ligada às políticas educacionais das esferas federal e estadual. De acordo com Ghiraldelli Jr. (1994), quando José Sarney assumiu o governo, herda, em termos educacionais, uma situação calamitosa. O número de analfabetos, fruto da política educacional da ditadura, crescera absurdamente; havia um crescente processo de privatização do ensino, em detrimen-

sentidos e códigos próprios, que são acionados para orientar as atividades e ações em seu interior e sua relação com o seu meio-ambiente (do qual fazem parte outros sistemas ou campos).

5 Em depoimento, uma ex-aluna atleta informou que não poderia dizer como eram as aulas de Educação Física porque simplesmente nunca havia participado de uma; era dispensada (legalmente).

Movimento, Porto Alegre, v. 11, n. 4, p.9-21, janeiro/abril de 2005 
to da escola pública (aliás, essa cresceu aquém das reais necessidades da população); o número de escolas privadas no terceiro grau também toma impulso; o magistério sofre com o sucateamento das escolas, com a má remuneração e com a evasão escolar. O descaso com a educação e, conseqüentemente, com os professores, era tal que a década de 80 foi marcada pelas greves no magistério, constituindo-se essa a única forma legítima de manifestação.

Nos depoimentos de professores, ex-professores e ex-alunos aparece claramente a percepção que eles tiveram desse processo de deterioração. Os entrevistados referem-se à década de 80 como a década das greves, e isso em função de a situação de degradação salarial e as precárias condições de trabalho terem atingido graus insuportáveis, redundando em dias e dias sem aulas, evasão de alunos da escola, disciplinas sem professores e aulas canceladas. É nesse contexto, na década de 80, que os professores retomam mais fortemente a atividade sindical organizada, motivados por um processo mais geral de organização sindical dos trabalhadores no Brasil. Destacamos, desse amplo processo, o fato de que a deterioração do ensino público propicia o avanço do ensino privado, e grandes camadas da população de classe média, que antes freqüentavam alguns prestigiados colégios públicos, migram para escolas privadas. Interessante é observar como isso se reflete no esporte do Colégio Estadual:

A classe média-alta freqüentava o Colégio Estadual como freqüentava o Instituto de Educação, então o nível social era muito importante, então isso trazia um conseqüência importante, porque esses alunos também freqüentavam clubes como suporte de treinamento. Hoje, praticamente a escola pública pega uma massa social de pobre para baixo (PROFESSOR G.)

Dessa forma, vários fatores de ordem externa acabaram determinando uma diminuição da atividade esportiva voltada às competições no Colégio Estadual, a partir de meados da década de 80 e durante a década de 90 . Por um lado, os recursos para contratar treinadores são cortados, a carga horária destinada ao treinamento é suprimida (depende do envio e aprovação pela SEDU de projeto específico), falta material esportivo adequado, o que é reflexo em parte da deterioração das condições gerais da educação pública; por outro lado, os próprios jogos escolares perderam prestígio no nível nacional - algumas edições dos jogos deixaram de ser realizadas, outras tiveram um caráter diferenciado, procurando-se diminuir sua dimensão competitiva entre os Estados - bem como no nível estadual (o DEARES, órgão responsável pela organização dos

Wovimento, Porto Alegre, v. 11, n. 4, p.9-21, janeiro/abril de 2005 
jogos escolares foi extinto na Secretaria Estadual de Educação no final da década de 90 e realocado na Secretaria de Cultura e Esportes), além do que a rivalidade e a superioridade das instituições privadas passou a dificultar conquistas expressivas por parte dos colégios públicos nos jogos.

Assim, chega-se ao final da década de 90 com o esporte voltado às competições e a própria disciplina de Educação Física do colégio em crise que se manifestou, concretamente, na tentativa de a Secretaria Estadual de Educação, uma vez facultado pela nova LDB de 1996, reduzir o número de aulas semanais de Educação Física de duas para uma. Esse fato parece indicar que a legitimidade da Educação Física no Colégio Estadual está fortemente questionada e seu prestígio estava vinculado ao sucesso do esporte voltado às competições. Embora nenhuma disciplina escolar possua presença naturalmente garantida no currículo, a Educação Física parece ser uma das disciplinas escolares mais questionadas quanto à sua legitimidade. Assim, poderíamos dizer que ela é constantemente "avaliada" com relação aos seus resultados e importância educacionais. Mas, a partir de quais parâmetros ela tem sido avaliada? No plano do imaginário social mais amplo, um episódio pode dar uma idéia dos parâmetros utilizados para tanto. Tratase do amplo debate em torno do fracasso do Brasil nas últimas Olimpíadas de Sidney (Austrália). Uma das possíveis causas aludidas e alardeadas teria sido o abandono da obrigatoriedade da Educação Física nas escolas. Citou-se muito o exemplo da jogadora de basquete Hortência que teria aprendido o esporte nas aulas de Educação Física. Iniciar esportivamente futuros campeões parece ser um parâmetro fundamental no imaginário social (e muitas vezes das autoridades esportivas e educacionais) para avaliar a importância da Educação Física. Basta dizer que esse foi o argumento "forte" para a "volta" da obrigatorie-dade da Educação Física nas escolas brasileiras.

Então, a solução para essa crise é percebida por alguns professores de Educação Física do colégio, no retorno ao passado glorioso e esportivo do colégio. Como observou Gariglio (2002, p. 74), para o caso do CEFET/MG, "[...] o passado surge como lembrança de momentos de glória, do reconhecimento pelos pares, dos projetos com êxito, do respeito conquistado perante a instituição, enfim, lembranças que remetem quase sempre ao sentimento de sucesso". Outras possibilidades de legitimação da Educação Física não são aventadas. Ainda segundo Gariglio (2002), a inércia das esco-

Movimento, Porto Alegre, v. 11, n. 4, p.9-21, janeiro/abril de 2005 
las no ordenamento do seu currículo passa pelo tempo necessário para a substituição do grupo de docentes. Nesse sentido, os "novos" professores de Educação Física do colégio, que travaram contato com os debates da chamada Pedagogia Crítica da Educação Física, esboçaram apenas tímidos movimentos no sentido de reorientar a disciplina no colégio. Uma das razões para tanto deve-se ao fato de que a contratação desses novos professores se dá em caráter precário, no regime chamado de Designação Temporária.

\section{Considerações finais}

A investigação do itinerário da disciplina Educação Física no Colégio Estadual do Espírito Santo, no período de 1970-2000, permitiu-nos ratificar alguns postulados dos estudos da história das disciplinas escolares. Entre eles, destacamos: a) as disciplinas escolares não são entidades naturais, suas existências e persistências nos currículos escolares são permanentemente contestadas; b) a sua existência, permanência e status na escola são dependentes de fatores internos à unidade escolar, mas também de fatores externos relativos à conjuntura sociopolítica mais geral. No caso da Educação Física no Colégio Estadual do Espírito Santo, ela tem se mostrado particularmente sensível à política esportiva nacional; c) as diversas disciplinas possuem status diferenciados no interior do currículo, estando a Educação Física do Colégio Estadual fortemente sujeita aos destinos do esporte voltado às competições.

Os dados obtidos indicam a existência de uma relação complexa entre a disciplina Educação Física e o esporte voltado às competições. No período estudado, percebemos o auge e a decadência do esporte escolar no Colégio Estadual, coincidindo esta última com uma mudança na política esportiva do País e com o agravamento da situação da educação pública de maneira geral, particularmente a deterioração das condições de trabalho dos professores e as conseqüentes greves, o que gerou, entre outras coisas, uma migração das classes médias para as escolas privadas. O declínio das atividades esportivas voltadas à competição no Colégio Estadual foi um dos fatores que afetaram o status e a legitimidade da disciplina Educação Física. O apelo a um retorno do esporte voltado à competição como forma de revalorizar a Educação Física (no sentido geral) no Colégio pode significar, na verdade, uma substituição da disciplina Educação Física (com conteúdo a ser transmitido, ensino sistemático com exercícios e

Movimento, Porto Alegre, v. 11, n. 4, p.9-21, janeiro/abril de 2005 
avaliação do aprendido) por uma atividade oferecida pelo Colégio fora dos marcos do chamado núcleo central do currículo.

\title{
Referências
}

\author{
Physical Education Itinerary at School: \\ Espírito Santo State School Case \\ Abstract: This research analyses the Physical Education \\ subject itinerary at Colegio Estatual in Espirito Santo, from \\ 1970 up to 2000 , aiming at indentifying the discourse made \\ by the school subject to be legitimated in that school \\ curriculum, at examining possible changes in the sense \\ of being present in the curriculum, at identifying the main \\ internal and external factors which influence the charac- \\ teristics assumed by the discipline, at analysing the \\ solutions thought to overcome the present discipline crisis \\ in the school. The study case indicates a strong legitimacy \\ and the Physical Education status dependence, of the \\ sports practice expanding and public politics towards \\ competitive sports. \\ Keywords: School diciplines, Physical Education, School.
}

\begin{abstract}
Itinerários de la Educacion Física em la Escuela: El caso del Colegio Estatal del Espírito Santo

Resumen: Esa investigación analiza el itinerario de la asignatura Educación Física en el Colegio Estatal del Espirito Santo (Vitória, Espírito Santo, Brasil), en el periodo de 1970 a 2000, buscando: identificar el discurso construido por esta para legitimarse en el currículo de aquella escuela; examinar los posibles cambios de sentido de su presencia en el curriculo; identificar los principales factores internos y externos que influyeron en las caracteristicas asumidas por la asignatura; analizar las soluciones pensadas para superar la actual crisis de la asignatura en dicho centro. El estudio de caso realizado indica una fuerte dependencia de la legitimidad y del status de la asignatura Educación Física, de los desdoblamientos de la práctica deportiva y de las políticas públicas volcadas hacia el deporte de competición.
\end{abstract}

Palabras clave: Asignaturas, Educación Física, Escuela.

Movimento, Porto Alegre, v. 11, n. 4, p.9-21, janeiro/abril de 2005 
Itinerários da Educação Física na Escola...

CAPARROZ, F. E. Entre a educação física na escola e a educação física da escola: a educação física como componente curricular. Vitória: CEFD/UFES, 1997.

CHERVEL, A. História das disciplinas escolares: reflexões sobre um campo de pesquisa. Teoria \& Educação, Porto Alegre, n. 2, 1990.

GARIGLIO, J. A. A educação física no currículo de uma escola profissionalizante: um caso sui generis. Revista Brasileira de Ciências do Esporte, v. 23, n. 2, p. 6988, 2002.

GOODSON, I. Tornando-se uma matéria acadêmica: padrões de explicação e evolução. Teoria \& Educação, Porto Alegre, n. 2, p. 230-255, 1990.

GHIRALDELLI JUNIOR., P. História da educação. 2 ed. São Paulo: Cortez, 1994.

JULIÁ, D. Disciplinas escolares: objetivos, ensino e apropriação. In: LOPES, A C.: MACEDO, E. (Org.). Disciplinas e integração curricular: história e políticas. Rio de Janeiro: DP\&A, 2002. p. 37-71.

OLIVEIRA, M A. T. de. A revista brasileira de educação física e desporto (19681984) e a experiência cotidiana de professores da rede municipal de ensino de Curitiba: entre a adesão e a resistência 2001. 399 f. Tese (Doutorado em História e Filosofia da Educação) - Pontifícia Universidade Católica, São Paulo, 2001.

PAIVA, F. S. L. de. Sobre o pensamento médico-higienista oitocentista e a escolarização: condições de possibilidade para o engendramento do campo da educação física no Brasil. 2003. 450 f. Tese (Doutorado em Educação) - Faculdade de Educação, Universidade Federal de Minas Gerais, Belo Horizonte, 2003.

SANTOS, L. L. de C. P. História das disciplinas escolares: perspectivas de análise. Teoria \& Educação, Porto Alegre, n. 2, p. 21-29, 1990.

VAGO, T. M. Cultura escolar, cultivo de corpos: Educação Physica e Gymnastica como práticas constitutivas dos corpos de crianças no ensino público primário de Belo Horizonte (1906-1920). 1999. 315 f. (Doutorado em Educação) - Faculdade de Educação, Universidade de São Paulo, São Paulo, 1999.

Movimento, Porto Alegre, v. 11, n. 4, p.9-21, janeiro/abril de 2005 